\title{
基于 IMS 网络的核心网能力开放部署方式
}

\section{Core Network Capability Open Deployment Mode Based on IMS Network}

\section{管相武}

\author{
Xiangwu Guan
}

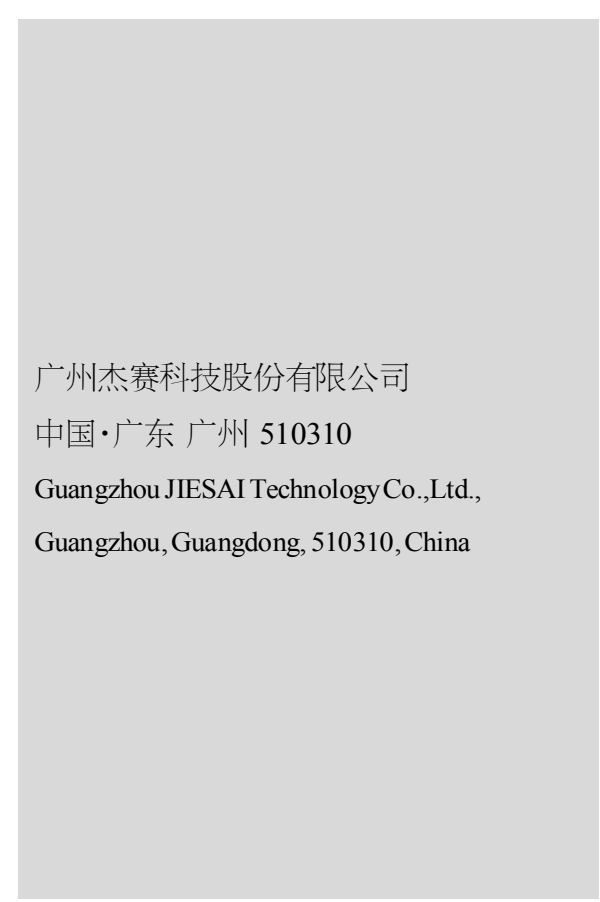

\section{1 引言}

在中国通信行业的发展中, 在因特网设备基础上发展起 来的移动设备和因特网通信是下一代通信行业发展的关键, 其具有高清晰度的平度、高内核处理性能、多样化的应用方 式。现阶段, 传统的用户终端单独调用资源获取应用的模式已 被淘汰, 新型的应用是在端对端的基础上获取资源, 如共享视 频和游戏等 ${ }^{[1]}$ 。同时, 传统的拨号通信方式已被快速地融入 IP 通信领域中, 以 IP 连接功能为基础的终端设备是未来通信行 业的重要趋势。

\section{2 中国移动通信网络的发展背景}

在社会的发展中, 移动通信网络已从 $2 \mathrm{G} / 3 \mathrm{G}$ 逐渐发展到 4GLTE, 移动核心网也逐渐由传统的核心网演进成了 $\mathrm{EPC}_{0}$ $\mathrm{EPC}$ 指的是演进的分组核心网, 其业务模式是统计用户使用 业务行为的一系列指标参数, 为构建网络建设规模提供了支 持, 合理的业务模型在网络规划、日常运营维护和优化过程中 发挥着指导作用。但是, 受各种不利因素的影响, 这种模型的 确立呈现出复杂性、多样性等特点。与传统的通信技术相比, 4GLTE 通信技术的通话质量、数据通信速度存在很大的优
势, 并对用户的使用习惯带来了很大影响, 新型的终端和业务 应用为用户提供了高速率的用户体验, 这就使得用户的行为 发生了很大改变, 严重影响着业务模型。此外, 很多非技术性 因素也使得 LTE 业务模型受到很大影响, 如运营商资费策 略、节假日优惠策略。

\section{IMS 承载控制}

\section{1 端到端 QoS 体系}

公共网络中普遍存在高延迟、顺序混乱和丢包问题, 极易 出现在 IMS 网络中。一般而言, 底层接人、传输层合作会提供 高质量的端到端服务, 且 IMS 端到端的服务质量体系能够确 保多媒体业务在 IP 网络中的传输质量, 其体系是在 IP 服务 质量体系的基础上建立的。

\subsection{SBLP 控制体系}

在设计 IMS 的过程中, 设计人员应该树立控制层和用户 层分离的理念, 但层与层之间是相互依赖的, 在用户层和控制 层不存在互操作性的情况下, 操作人员将无法有效地控制 QoS、IMS 源端和目的端的媒体传输和媒体传输起始时间, 这 就使得为 IMS 媒体传输授权、控制承载传输使用量的机制应 


\section{信息与通信 Information and Communication}

运而生, 且 GPRS 和 IMS 之间相互操作的整体框架被称为基 于本地服务策略控制, 这是在 3GPP 定义的基础上建立的承 载控制体系, 图 1 是 SBLP 体系相关的功能实体图。

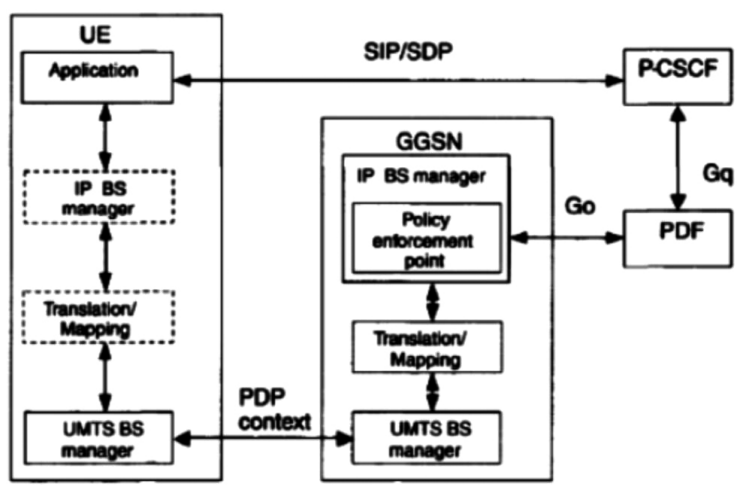

图 1 SBLP 承载控制体系

\section{4 影响 IMS 核心网安全的因素}

\section{1 网络因素}

首先, IMS 网络信令类型指的是 SIP、DNS、Diameter 信令 等, 各项信令的有效处理在很大程度上反映出了各项链路传 送的可靠性、网络层面信令处理的安全性和可用性; 其次, 在 承载网络的过程中，相关人员应该注重媒体流传输通道的安 全性和可靠性; 再次, IMS 网络能够提供形式多样的接入终 端, 这就需要加强对接入层面安全性的重视, 而接入类指标在 很大程度上反映出网络侧设备被接入侧设备攻击的实际情 况、BAC 安全防护和性能运行等; 最后, 网络资源的完好性在 很大程度上反映出网络运行的安全性和可靠性, 如设备和链 路的完好率、时钟偏差等。

\section{2 话务因素}

首先，在一定时间内，很多用户都能够同时拨打用户号 码, 但受用户资源不足、电路故障等影响, 极易出现话务溢出 问题; 其次,在遇到突发事件的情况下,很多用户会重新发起 注册流程, 这就使得系统的负荷有所增加; 最后, 在升版割接、 局数据配置、话务调整的过程中,往往会因设计不合理或评估 不足, 影响话务的实际分布, 从而出现话务拥堵问题。

\section{3 设备因素}

设备运行的稳定性、设备资源, 如内存、媒体带宽、IP 端 口等占用情况、设备几余以及设备控制制度的完善性,都在很 大程度上影响着网络运行的安全性。

\section{4 容灾因素}

网络环境相对比较复杂, 这就会引发一系列异常问题,如 设备宕机、网络阻断等, 且网络中的容灾等功能也会对业务提 供的连续性造成一定的影响。

\section{IMS 核心网络能力平台建设方案}

在现代化社会经济快速发展时期, 为了满足市场的实际 需求, 通过分析现有的部署案例, 核心网络实时音视频网络对 能力开发提出了更加严格的要求, 并遵循优先发展的实际需 求。同时,短信能力平台需要在短信平台的基础上进行升级和 支持。本文结合基本音视频能力平台建设的实际情况, 提出了 核心网能力平台建设方案。如图 2 所示, 基础语音 AS, 如 VoLTE AS、统一 Centrex AS 等升级是能力平台, 其能够向 IMS 用户提供在 IMS 基础上发展的多媒体电话业务, 如基本 语音业务、视频业务、呼口情移、多方通话和传真业务等。相关 人员可以根据用户的实际需求, 合理地配置相关模块, 确保各 项业务功能的有效拓展, 如配置 VPMN 业务模块提供融合 VPMN 业务等。同时,技术人员需要根据基础语音 AS 支持功 能, 基础语音 AS 具备升级是基本音视频业务能力平台的可 行性。除此之外, IMS 网络是由归属区域实现业务控制的, 这 就需要向用户提供归属区域特色能力开发业务, 如在 VoLTE 用户回落至 $2 \mathrm{G} / 3 \mathrm{G}$ 网络的过程中, 主叫需要由 $2 \mathrm{G} / 3 \mathrm{G}$ 网络进 行疏通, 无需由归属 VoLTE AS 进行呼口丩控制, 这时在主口L侧 将无法实现由 VoLTE AS 提供的能力开放业务 ${ }^{[2]}$ 。

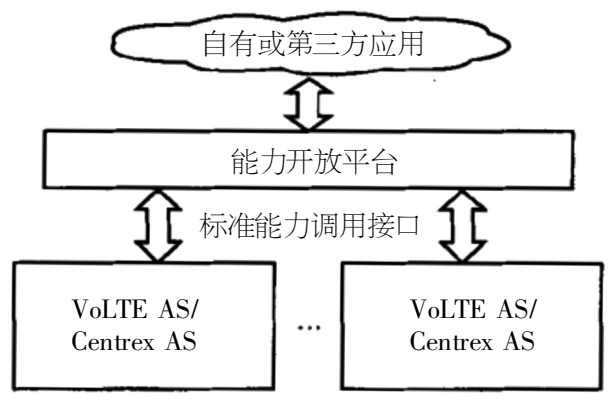

图 2 基础语音 $\mathrm{AS}$ 升级作为能力平台方案

\section{6 结语}

综上所述, 相关人员在应用 IMS 核心网的过程中, 应该 加强对网络安全问题的重视, 并建立网络安全指标体系, 设计 相应的指标, 如网络安全指标、话务安全指标、设备安全指标 等, 并加强对各项指标的有效评估, 及时发现并解决网络中存 在的问题。因此, 在建设 IMS 核心网的过程中, 相关人员需要 建立网络安全指标体系, 实现对核心网的有效管理。

\section{参考文献}

[1] 邱巍, 吴倩, 吴海. 基于 IMS 网络的核心网能力开放部署方式 [J].电信科学,2017(4):155-162.

[2]李丹丹.基于 IMS 的核心网演进分析及研究[J].科技创新与应 用,2017(16):95. 